\title{
Multimorbidity and health-related quality of life in Koreans aged 50 or older using KNHANES 2013-2014
}

\author{
Bomi Park', Minsu Ock², Hye Ah Lee ${ }^{3}$, Seonhwa Lee ${ }^{1}$, Hyejin Han ${ }^{1}$, Min-Woo Jo ${ }^{4}$ and Hyesook Park ${ }^{1 *}$ (D)
}

\begin{abstract}
Background: Multimorbidity negatively affects health outcomes and impairs health-related quality of life (HRQoL). We assessed the prevalence of multimorbidity in Koreans aged 50 and older, taking into consideration their socioeconomic status, and estimated the loss in HRQoL due to multimorbidity.

Methods: This study is based on an analysis of data for adults aged 50 and older derived from the cross-sectional nationally representative Korean National Health and Nutrition Examination Survey conducted in 2013-14. The five most prevalent chronic diseases and disease dyads were identified. The impact of the degree of multimorbidity, sex, and socioeconomic status on the European Quality of Life 5 Dimension (EQ-5D) index score were analyzed. Marital status, educational attainment, household income, basic livelihood security benefit, and occupation were considered as socioeconomic factors.
\end{abstract}

Results: The analysis included 5996 adults aged 50 years and older with males comprising 46.6\%. Two or more chronic diseases were present in $26.8 \%$ of the participants aged 50 and older and $37.9 \%$ of the participants aged 65 and older. The most prevalent dyadic combination was hypertension and dyslipidemia in the 50 and older group, and hypertension and osteoarthritis in the 65 and older age group. Hypertension dominated the multimorbidity combinations (four of the five most prevalent multimorbidity dyads), while a few conditions such as osteoarthritis had a relatively large influence on quality of life. In addition to the degree of multimorbidity, female and lower socioeconomic status were associated with significantly lower EQ-5D index scores.

Conclusions: Integrated, holistic healthcare based on a patient-oriented perspective for earlier, more effective intervention, targeting multimorbidity is warranted. Special consideration should be given to patients with low socioeconomic status.

Keywords: Multimorbidity, Health-related quality of life, Prevalence, Socioeconomic disparity

\section{Background}

Multimorbidity is defined as the simultaneous presence of two or more diseases in the same individual [1]. With technological advances and improvements in medical care and public policy, chronic medical conditions have overtaken infectious diseases as the dominant cause of death and disability. This phenomenon, in parallel with the aging population, has led to an increase in the number

\footnotetext{
* Correspondence: hpark@ewha.ac.kr

${ }^{1}$ Department of preventive medicine, School of Medicine, Ewha Womans

University, Seoul, South Korea

Full list of author information is available at the end of the article
}

of individuals who present with multimorbidity of chronic diseases $[2,3]$.

Multimorbidity is important for both patients and the healthcare system, and a great public health concern, because multimorbidity is associated with higher mortality $[4,5]$, reduced functional status [6], lower quality of life [7], longer hospitalization, higher readmission, more frequent healthcare utilization, and higher healthcare costs [8-10].

Since chronic conditions are controlled rather than cured, the amount of multimorbidity has a large influence on the quality of life until death. Previous studies reported high prevalence rates of multimorbidity in older people

(c) The Author(s). 2018 Open Access This article is distributed under the terms of the Creative Commons Attribution 4.0 International License (http://creativecommons.org/licenses/by/4.0/), which permits unrestricted use, distribution, and reproduction in any medium, provided you give appropriate credit to the original author(s) and the source, provide a link to the Creative Commons license, and indicate if changes were made. The Creative Commons Public Domain Dedication waiver (http://creativecommons.org/publicdomain/zero/1.0/) applies to the data made available in this article, unless otherwise stated. 
ranging from 55 to $98 \%$ in different settings, as well as an inverse relationship between multimorbidity and quality of life $[2,11]$. However, little is known about socioeconomic inequalities in quality of life in the context of multimorbidity. In addition, only a few Korean studies have focused on multimorbidity, even though Korea is an aged society where an estimated $28.7 \%$ of the population will be older than 65 years by 2035 and $42.5 \%$ by 2065 [12]. Therefore, this study investigated the prevalence of multimorbidity among Koreans aged 50 or older and explored whether the number of co-occurring chronic conditions in concert with socioeconomic status affect the quality of life of those with multimorbidity.

\section{Methods}

\section{Data source}

This study is based on an analysis of adults aged 50 and older using data derived from the 6th Korean National Health and Nutrition Examination Survey (KNHANES) conducted in 2013-14. KNHANES is a series of crosssectional national surveys of the noninstitutionalized Korean population administered by the Division of Chronic Disease Surveillance of the Korean Centers for Disease Control and Prevention (KCDC), and consists of a health interview, health examination, and nutrition survey. KNHANES used a complex, stratified, multistage cluster sampling method based on geographical area, gender, and age to secure a representation of the Korean population. Primary sampling units (PSUs) were drawn from a sampling frame of all census blocks or resident registration addresses, and then households were sampled for each PSU using systematic sampling. In the selected households, individuals aged 1 year and over were targeted. This study was approved by the institutional review board of KCDC (2013-07CON-03-4C, 2013-12EXP-03-5C), and written informed consent to participate in the study was obtained from all participants.

\section{Chronic diseases}

Multimorbidity was defined as having two or more of 25 chronic diseases pre-specified in KNHANES: hypertension, dyslipidemia, stroke, myocardial infarction, angina, osteoarthritis, rheumatic arthritis, tuberculosis, asthma, allergic rhinitis, depression, kidney failure, atopic dermatitis, diabetes mellitus, thyroid disease, stomach cancer, liver cancer, colon cancer, breast cancer, cervical cancer, lung cancer, thyroid cancer, hepatitis $\mathrm{B}$, hepatitis $\mathrm{C}$, and liver cirrhosis. The presence of disease was determined based on self-reports of whether the participants had ever been diagnosed with each disease by a physician and either currently had that disease or were under treatment for that disease.

\section{Health related quality of life}

Health related quality of life (HRQoL) was assessed using the EuroQol 5 Dimensions (EQ-5D), a generic measure of HRQoL that can be used to describe and value health states. The EQ-5D consists of five dimensions (mobility, self-care, usual activities, pain or discomfort, and anxiety or depression) with three response levels for each dimension (no problem, moderate problem, and severe problem) generating a total of 243 different health states. The EQ-5D produces a single utility value of a given health state on a scale where 0 indicates death, 1 indicates perfect health, and negative values indicate health states worse than death. The utility value was transformed from the EQ-5D response using the Korean EQ-5D-3 L-value set [13].

\section{Socioeconomic factors}

We considered the following socioeconomic factors: marital status, educational attainment, household income, basic livelihood security benefit, and occupation. Marital status was divided into two categories: married and unmarried (single, separated, divorced, or widowed). Educational attainment was categorized into two groups. A high school degree or less was defined as low educational attainment for those aged less than 70 , while a middle school degree or less was defined as low for those aged 70 years and older. The household income was calculated by dividing the household monthly income by the square root of the household size [14], and then categorized into quartiles, with 1 being the lowest and 4 being the highest. The cut-off values for quartiles were 667.70, 1335.41, and 2192.82 US dollars in 2013 and 605.92, 1376.96, and 2225.68 US dollars in 2014. Occupation status was categorized into unemployed, blue-collar worker, and white-collar worker. Blue-collar worker includes service workers or retailers, agriculture or fishery employees, technicians, mechanics, or assemblers, and simple laborers. White-collar worker includes managers, professionals, and office workers.

\section{Statistical analysis}

Descriptive analysis was performed for the participants' socioeconomic and clinical characteristics. Because of the non-normal distribution of the EQ-5D index score, it was log-transformed before further analysis and the EQ-5D index scores are presented as geometric means with the 95\% confidence intervals (CIs) after back-transformation. All estimates were weighted to account for the complex survey design, so that the results would be representative of the entire Korean population. Participants' sociodemographic and clinical characteristics are presented as the sample-weighted percentage of the population with the standard error (SE) or the sample-weighted geometric mean with the $95 \% \mathrm{CI}$. The percentage of multimorbidity 
and EQ-5D index score across socioeconomic status was estimated. The five most prevalent chronic diseases and disease dyads were identified within each age group and stratified by sex, and the prevalence rate was defined as the total number of cases divided by the average registered population of Korean residents in 2013 and 2014.

Estimates of the least square means for EQ-5D index score with $95 \%$ CIs by the number of chronic conditions and socioeconomic status (marital status, educational attainment, household income, basic livelihood security benefit, and occupation) were calculated using regression analysis with SAS PROC SURVEYREG. In an adjusted model, least square means for EQ-5D index score with 95\% CIs by the number of chronic conditions were adjusted for marital status, education, household income, basic livelihood security recipient status, and occupation. Sex was additionally adjusted in analyses with the total population, including both sexes.

All analyses were repeated with only participants aged 65 and older to specifically investigate the aged population. All tests were two-tailed, and a $p$-value $<0.05$ was regarded as statistically significant. All statistical analyses were performed using SAS (ver. 9.4; SAS Institute, Cary, $\mathrm{NC}$, USA) with the survey procedure.

\section{Results}

The sample consisted of 5996 (weighted frequency $16,591,498)$ participants aged 50 years and older $(46.6 \%$ male) and 2856 (weighted frequency 6,261,631) participants aged 65 years and older $(41.5 \%$ male). The mean age of the study population was 62.7 (95\% CI 62.3-63.0) years. Table 1 presents the sociodemographic and clinical characteristics according to age group and sex.

Among the participants aged 50 and older, 26.8\% (SE, $0.8)$ reported having two or more chronic diseases and $11.0 \%$ (SE, 0.5) reported having three or more chronic diseases from the 25-item list. In addition, 37.9\% (SE, 1.3) of the Koreans aged 65 and older reported having two or more chronic diseases and 17.6\% (SE, 0.9) reported having three or more chronic diseases from the list.

The geometric mean EQ-5D index score was 0.89 (95\% CI, 0.89-0.90) for 50 and older, and 0.83 (95\% CI, $0.82-0.84)$ for 65 and older. The EQ-5D index score was significantly lower among women $(p<0.0001)$ for both age groups (Table 1 ).

Of those aged 50 and older, the multimorbidity percentage was significantly higher and the EQ-5D index scores were significantly lower in those who are currently single, those who attained a lower education level, those living in the lowest house income quartile, those who received basic livelihood security, and those who are unemployed. The same pattern was seen in the 65 and older age group (Table 2).
Table 3 shows the five most prevalent chronic diseases and their EQ-5D index scores when the participants reported having only one disease. Among the participants aged 50 and older, the five most prevalent diseases were hypertension (107.55 per 1000 people), osteoarthritis (47.24 per 1000 people), diabetes mellitus (25.21 per 1000 people), dyslipidemia (23.23 per 1000 people), and allergic rhinitis (20.72 per 1000 people). The participants aged 65 and older showed a similar pattern, except that depression was the fifth most prevalent disease, rather than allergic rhinitis.

There were no differences between men and women in the lists of the five most prevalent diseases, but the rank order of the lists differed. Men had higher prevalences of hypertension (121.24 per 1000 vs. 95.41 per 1000), diabetes mellitus (39.49 per 1000 vs. 12.66 per 1000), and allergic rhinitis (25.83 per 1000 vs. 16.22 per 1000 ), while women had higher prevalences of osteoarthritis (65.08 vs. 26.96 per 1000) and dyslipidemia (29.72 vs. 15.85 per 1000) (Table 3).

Table 4 shows the five most prevalent dyadic combinations and their EQ-5D index scores. The disease dyads most commonly observed among the 50 and older age group were hypertension and dyslipidemia (27.89 per 1000), followed by hypertension and diabetes mellitus (25.14 per 1000), while the 65 and older age group experienced the combination of hypertension and osteoarthritis the most (42.73 per 1000), followed by hypertension and diabetes mellitus (42.50 per 1000). The most frequent individual chronic disease, hypertension, dominated the dyadic combinations and was present in four out of the top five prevalent dyads for both age groups.

Hypertension was the most frequent single chronic disease, but the EQ-5D index score was the lowest for osteoarthritis in both age groups and both sexes (Table 3), and the combination of hypertension and osteoarthritis had the lowest EQ-5D index score out of the top five most prevalent dyads for both men and women (Table 4).

The associations between the number of chronic diseases or socioeconomic status with the EQ-5D index score were analyzed, and the results are summarized in Table 5. The least square mean of EQ-5D index score for those who had more chronic diseases was significantly lower compared with the reference group for both age groups and sex. Regarding socioeconomic status, unmarried status, lower education level, lower household income, basic livelihood security recipient status, and unemployed status were associated with a lower EQ-5D index score (Table 5). When we considered sex, the number of chronic conditions and socioeconomic status together in one model, female, greater number of chronic conditions, and lower socioeconomic 
Table 1 Participants' sociodemographic and clinical characteristics by gender

\begin{tabular}{|c|c|c|c|c|c|c|c|c|}
\hline \multirow[t]{2}{*}{ Variable } & \multicolumn{4}{|l|}{50 and older } & \multicolumn{4}{|l|}{65 and older } \\
\hline & Total & Male & Female & $p$-value & Total & Male & Female & $p$-value \\
\hline \multicolumn{9}{|c|}{ Number of chronic conditions } \\
\hline 0 & $46.6(0.9)$ & $52.4(1.2)$ & $41.5(1.1)$ & $<0.0001$ & $32.9(1.2)$ & $38.7(1.7)$ & $28.7(1.5)$ & $<0.0001$ \\
\hline 1 & $26.6(0.7)$ & $27.2(1.1)$ & $26.1(0.9)$ & & $29.2(1.1)$ & $32.9(1.6)$ & $26.5(1.3)$ & \\
\hline 2 & $15.7(0.6)$ & $12.7(0.8)$ & $18.4(0.8)$ & & $20.3(0.9)$ & $17.4(1.2)$ & $22.4(1.2)$ & \\
\hline 3 & $7.0(0.4)$ & $5.1(0.5)$ & $8.7(0.6)$ & & $10.8(0.7)$ & $7.3(0.9)$ & $13.2(1.0)$ & \\
\hline $4+$ & $4.0(0.3)$ & $2.6(0.3)$ & $5.3(0.5)$ & & $6.9(0.6)$ & $3.7(0.6)$ & $9.1(0.9)$ & \\
\hline EQ-5D index score & $0.89(0.89-0.90)$ & $0.93(0.92-0.93)$ & $0.87(0.86-0.88)$ & $<0.0001$ & $0.83(0.82-0.84)$ & $0.88(0.86-0.90)$ & $0.79(0.78-0.81)$ & $<0.0001$ \\
\hline \multicolumn{9}{|l|}{ Current marital status } \\
\hline Married & $76.8(0.8)$ & $88.5(0.9)$ & $66.5(1.0)$ & $<0.0001$ & $62.1(1.2)$ & $88.1(1.1)$ & $43.7(1.4)$ & $<0.0001$ \\
\hline Unmarried & $23.2(0.8)$ & $11.5(0.9)$ & $33.5(1.0)$ & & $37.9(1.2)$ & $11.9(1.1)$ & $56.3(1.4)$ & \\
\hline \multicolumn{9}{|l|}{ Education $^{a}$} \\
\hline High & $17.8(0.9)$ & $26.8(1.3)$ & $10.1(0.8)$ & $<0.0001$ & $15.7(1.0)$ & $28.0(1.7)$ & $6.8(0.8)$ & $<0.0001$ \\
\hline Low & $82.2(0.9)$ & $73.2(1.3)$ & $89.9(0.8)$ & & $84.3(1.0)$ & $72.0(1.7)$ & $93.2(0.8)$ & \\
\hline \multicolumn{9}{|l|}{ Household income $^{b}$} \\
\hline Quartile 4 & $23.8(1.1)$ & $26.3(1.3)$ & $21.6(1.1)$ & $<0.0001$ & $9.9(0.8)$ & $11.9(1.2)$ & $8.4(0.9)$ & $<0.0001$ \\
\hline Quartile 3 & $22.3(0.8)$ & $24.6(1.0)$ & $20.3(0.9)$ & & $13.2(0.9)$ & $15.3(1.2)$ & $11.7(1.0)$ & \\
\hline Quartile 2 & $25.8(0.9)$ & $26.6(1.1)$ & $25.1(1.0)$ & & $25.9(1.2)$ & $29.0(1.6)$ & $23.7(1.2)$ & \\
\hline Quartile 1 & $28.1(1.1)$ & $22.5(1.1)$ & $33.0(1.3)$ & & $51.0(1.6)$ & $43.7(1.9)$ & $56.2(1.7)$ & \\
\hline \multicolumn{9}{|c|}{ Basic livelihood security recipients } \\
\hline No & $94.6(0.6)$ & $95.5(0.7)$ & $93.9(0.7)$ & 0.01 & $91.5(1.0)$ & $94.0(1.0)$ & $89.7(1.2)$ & 0.0004 \\
\hline Yes & $5.4(0.6)$ & $4.5(0.7)$ & $6.1(0.7)$ & & $8.5(1.0)$ & $6.0(1.0)$ & $10.3(1.2)$ & \\
\hline \multicolumn{9}{|l|}{ Occupation } \\
\hline White-collar & $10.9(0.7)$ & $17.1(1.1)$ & $5.5(0.5)$ & $<0.0001$ & $2.9(0.4)$ & $6.0(1.0)$ & $0.6(0.2)$ & $<0.0001$ \\
\hline Blue-collar & $42.3(1.0)$ & $50.3(1.5)$ & $35.4(1.1)$ & & $27.3(1.2)$ & $33.1(1.9)$ & $23.1(1.3)$ & \\
\hline Unemployed & $46.8(1.0)$ & $32.5(1.3)$ & $59.1(1.1)$ & & $69.8(1.3)$ & 60.9 (1.9) & $76.2(1.3)$ & \\
\hline
\end{tabular}

Values are presented as \% of population (standard error) or geometric mean (95\% confidence interval)

There was some overlap in the population between the two age groups with different age cut-off values

EQ-5D, European Quality of Life 5 Dimension

aducation: low: High school or under for 50-69 years of age and middle school or under for 70 and older years of age; high: college or higher for 50-69 years of age and high school or higher for 70 and older years of age

${ }^{b}$ Household income: household monthly income $/ \sqrt{\text { the household size }}$

status were still significantly associated with a lower EQ-5D index score (Table 6).

\section{Discussion}

This study found that the degree of multimorbidity was higher in the older age group. More than one-fourth of the population aged 50 years and older have at least two chronic conditions at once and nearly two out of five elderly aged 65 years and older live with multimorbidity, suggesting that multimorbidity is a common problem in Korean elderly.

Quality of life as measured by the EQ-5D index decreases significantly as the number of comorbid medical conditions increases. Furthermore, a few conditions, such as osteoarthritis, had a larger influence on the quality of life, which suggests that managing key chronic diseases to improve quality of life in the older population is important. We also found that lower socioeconomic status was associated with more prevalent multimorbidity and a lower EQ-5D index score.

With the aging of the population, the prevalence of chronic diseases is increasing and the chance of experiencing co-occurrence of multiple chronic diseases among the elderly population is increasing accordingly. The socioeconomic and disease burdens of multimorbidity are expected to increase considerably due to the rapidly aging population, because patients with multimorbidity are more likely to experience adverse health outcomes, frequent health services, and higher medical costs $[4,5,8-10]$. Therefore, multimorbidity is a very important public health issue that needs to be addressed. 
Table 2 Presence of multimorbidity and EQ-5D index score by sociodemographic characteristics

\begin{tabular}{|c|c|c|c|c|}
\hline \multirow[t]{3}{*}{ Variable } & \multicolumn{2}{|l|}{50 and older } & \multirow{2}{*}{$\begin{array}{l}65 \text { and older } \\
\% \text { of } \\
\text { multimorbidity }\end{array}$} & \multirow[b]{2}{*}{$\begin{array}{l}\text { EQ-5D index } \\
\text { score }\end{array}$} \\
\hline & $\begin{array}{l}\% \text { of } \\
\text { multimorbidity }\end{array}$ & $\begin{array}{l}\text { EQ-5D index } \\
\text { score }\end{array}$ & & \\
\hline & (SE) & Mean $(95 \% \mathrm{Cl})$ & (SE) & Mean $(95 \% \mathrm{Cl})$ \\
\hline \multicolumn{5}{|c|}{ Current marital status } \\
\hline Married & $24.1(0.8)$ & $0.92(0.91-0.92)$ & $35.7(1.4)$ & $0.86(0.85-0.88)$ \\
\hline Unmarried & $35.7(1.6)$ & $0.81(0.80-0.83)$ & $41.8(2.0)$ & $0.78(0.75-0.80)$ \\
\hline \multicolumn{5}{|l|}{ Education $^{\mathrm{a}}$} \\
\hline High & $22.4(1.7)$ & $0.95(0.94-0.96)$ & $38.0(2.8)$ & $0.92(0.90-0.94)$ \\
\hline Low & $31.3(0.9)$ & $0.88(0.87-0.89)$ & $43.7(1.5)$ & $0.82(0.80-0.83)$ \\
\hline \multicolumn{5}{|c|}{ Household income $e^{b}$} \\
\hline Quartile 4 & $19.6(1.4)$ & $0.95(0.94-0.96)$ & $37.1(3.5)$ & $0.90(0.88-0.93)$ \\
\hline Quartile 3 & $23.5(1.4)$ & $0.93(0.93-0.94)$ & $38.6(2.8)$ & $0.88(0.86-0.90)$ \\
\hline Quartile 2 & $26.6(1.2)$ & $0.90(0.89-0.91)$ & $37.0(1.9)$ & $0.86(0.83-0.88)$ \\
\hline Quartile 1 & $35.9(1.5)$ & $0.81(0.79-0.83)$ & $38.7(1.7)$ & $0.79(0.77-0.81)$ \\
\hline \multicolumn{5}{|c|}{ Basic livelihood security recipients } \\
\hline No & $25.9(0.8)$ & $0.90(0.90-0.91)$ & $36.9(1.3)$ & $0.85(0.83-0.86)$ \\
\hline Yes & $42.5(2.8)$ & $0.72(0.67-0.76)$ & $50.0(3.5)$ & $0.67(0.61-0.74)$ \\
\hline \multicolumn{5}{|l|}{ Occupation } \\
\hline White-collar & $14.7(1.9)$ & $0.97(0.96-0.97)$ & $26.9(6.0)$ & $0.95(0.92-0.97)$ \\
\hline Blue-collar & $23.0(1.1)$ & $0.93(0.92-0.94)$ & $34.8(2.1)$ & $0.88(0.86-0.89)$ \\
\hline Unemployed & $39.3(1.1)$ & $0.84(0.83-0.86)$ & $46.5(1.5)$ & $0.81(0.79-0.83)$ \\
\hline
\end{tabular}

$N$ Number, SE Standard Error, EQ-5D European Quality of Life 5 Dimension, $\mathrm{Cl}$ Confidence Interval

aEducation: low: High school or under for 50-69 years of age and middle school or under for 70 and older years of age; high: college or higher for 5069 years of age and high school or higher for 70 and older years of age

${ }^{b}$ Household income: household monthly income $/ \sqrt{\text { the household size }}$

Table 3 Prevalence and EQ-5D index score of the 5 most prevalent chronic conditions

\begin{tabular}{|c|c|c|c|c|c|}
\hline \multicolumn{3}{|l|}{50 and older } & \multicolumn{3}{|l|}{65 and older } \\
\hline Disease & Prevalence (per 1000) & EQ-5D index score $(95 \% \mathrm{Cl})$ & Disease & Prevalence (per 1000) & EQ-5D index score $(95 \% \mathrm{Cl})$ \\
\hline \multicolumn{6}{|l|}{ All } \\
\hline Hypertension & 107.55 & $0.92(0.90-0.93)$ & Hypertension & 151.41 & $0.88(0.86-0.90)$ \\
\hline Osteoarthritis & 47.24 & $0.83(0.80-0.86)$ & Osteoarthritis & 58.21 & $0.78(0.73-0.83)$ \\
\hline Diabetes mellitus & 25.21 & $0.92(0.90-0.95)$ & Diabetes mellitus & 27.08 & $0.91(0.87-0.96)$ \\
\hline Dyslipidemia & 23.23 & $0.92(0.90-0.94)$ & Dyslipidemia & 18.23 & $0.87(0.81-0.93)$ \\
\hline Allergic rhinitis & 20.72 & $0.95(0.94-0.97)$ & Depression & 6.25 & $0.85(0.83-0.88)$ \\
\hline \multicolumn{6}{|l|}{ Male } \\
\hline Hypertension & 121.24 & $0.93(0.91-0.95)$ & Hypertension & 183.70 & $0.90(0.87-0.94)$ \\
\hline Diabetes mellitus & 39.49 & $0.94(0.92-0.96)$ & Diabetes mellitus & 47.46 & $0.94(0.90-0.98)$ \\
\hline Osteoarthritis & 26.96 & $0.85(0.79-0.92)$ & Osteoarthritis & 43.64 & $0.82(0.73-0.92)$ \\
\hline Allergic rhinitis & 25.83 & $0.97(0.95-0.99)$ & Allergic rhinitis & 12.08 & $0.94(0.89-1.00)$ \\
\hline Dyslipidemia & 15.85 & $0.93(0.88-0.98)$ & Dyslipidemia & 11.25 & $0.83(0.65-1.05)$ \\
\hline \multicolumn{6}{|l|}{ Female } \\
\hline Hypertension & 95.51 & $0.90(0.88-0.92)$ & Hypertension & 128.49 & $0.86(0.83-0.89)$ \\
\hline Osteoarthritis & 65.08 & $0.83(0.79-0.86)$ & Osteoarthritis & 68.55 & $0.76(0.70-0.82)$ \\
\hline Dyslipidemia & 29.72 & $0.91(0.89-0.94)$ & Dyslipidemia & 23.18 & $0.89(0.85-0.93)$ \\
\hline Allergic rhinitis & 16.22 & $0.93(0.90-0.96)$ & Diabetes mellitus & 12.61 & $0.84(0.72-0.99)$ \\
\hline Diabetes mellitus & 12.66 & $0.87(0.80-0.94)$ & Depression & 7.53 & $0.82(0.80-0.83)$ \\
\hline
\end{tabular}


Table 4 Prevalence and EQ-5D index score of the 5 most prevalent chronic disease dyads

\begin{tabular}{|c|c|c|c|c|c|}
\hline \multicolumn{3}{|l|}{50 and older } & \multicolumn{3}{|l|}{65 and older } \\
\hline Disease combination & $\begin{array}{l}\text { Prevalence } \\
\text { (per 1000) }\end{array}$ & $\begin{array}{l}\text { EQ-5D index score } \\
(95 \% \mathrm{Cl})\end{array}$ & Disease combination & $\begin{array}{l}\text { Prevalence } \\
\text { (per 1000) }\end{array}$ & $\begin{array}{l}\text { EQ-5D index score } \\
(95 \% \mathrm{Cl})\end{array}$ \\
\hline \multicolumn{6}{|l|}{ All } \\
\hline Hypertension and Dyslipidemia & 27.89 & $0.93(0.91-0.95)$ & Hypertension and Osteoarthritis & 42.73 & $0.78(0.74-0.82)$ \\
\hline Hypertension and Diabetes mellitus & 25.14 & $0.87(0.82-0.93)$ & Hypertension and Diabetes mellitus & 42.50 & $0.84(0.76-0.92)$ \\
\hline Hypertension and Osteoarthritis & 23.35 & $0.81(0.77-0.85)$ & Hypertension and Dyslipidemia & 28.05 & $0.93(0.91-0.96)$ \\
\hline Dyslipidemia and Diabetes mellitus & 7.61 & $0.94(0.90-0.98)$ & Osteoarthritis and Diabetes mellitus & 7.39 & $0.79(0.72-0.87)$ \\
\hline Hypertension and Allergic rhinitis & 6.57 & $0.95(0.92-0.97)$ & Hypertension and Stroke & 7.35 & $0.72(0.61-0.86)$ \\
\hline \multicolumn{6}{|l|}{ Male } \\
\hline Hypertension and Diabetes mellitus & 30.04 & $0.86(0.77-0.96)$ & Hypertension and Diabetes mellitus & 52.80 & $0.82(0.69-0.98)$ \\
\hline Hypertension and Dyslipidemia & 23.25 & $0.94(0.91-0.98)$ & Hypertension and Dyslipidemia & 27.92 & $0.96(0.92-0.99)$ \\
\hline Dyslipidemia and Diabetes mellitus & 8.90 & $0.96(0.95-0.98)$ & Hypertension and Osteoarthritis & 16.33 & $0.80(0.66-0.97)$ \\
\hline Hypertension and Osteoarthritis & 8.09 & $0.82(0.71-0.94)$ & Hypertension and Stroke & 7.95 & $0.86(0.79-0.93)$ \\
\hline Hypertension and Allergic rhinitis & 7.77 & $0.94(0.88-1.01)$ & Hypertension and Angina & 6.06 & $0.95(0.77-1.17)$ \\
\hline \multicolumn{6}{|l|}{ Female } \\
\hline Hypertension and Osteoarthritis & 36.76 & $0.81(0.77-0.85)$ & Hypertension and Osteoarthritis & 61.46 & $0.77(0.73-0.81)$ \\
\hline Hypertension and Dyslipidemia & 31.96 & $0.92(0.90-0.95)$ & Hypertension and Diabetes mellitus & 35.19 & $0.86(0.83-0.89)$ \\
\hline Hypertension and Diabetes mellitus & 20.82 & $0.89(0.86-0.92)$ & Hypertension and Dyslipidemia & 28.14 & $0.92(0.89-0.95)$ \\
\hline Dyslipidemia and Osteoarthritis & 10.41 & $0.86(0.83-0.89)$ & Osteoarthritis and Diabetes mellitus & 11.73 & $0.79(0.71-0.88)$ \\
\hline Osteoarthritis and Allergic rhinitis & 8.02 & $0.88(0.83-0.94)$ & Dyslipidemia and Osteoarthritis & 8.71 & $0.85(0.81-0.89)$ \\
\hline
\end{tabular}

EQ-5D index score was presented as geometric mean $(95 \% \mathrm{Cl})$

The prevalence of multimorbidity seen in our results is in line with other studies, the majority of which reported prevalences of multimorbidity of $20-60 \%$, compared with $26.8 \%$ for age 50 and older and $37.9 \%$ for age 65 and older in our study [15-21]. The variation in the estimated prevalence of multimorbidity is likely to be due to differences in the set of diseases included, how multimorbidity is defined, population characteristics included, clinical setting, and database used [22].

Our results regarding the epidemiology of multimorbidity highlight the need to face the challenge of multimorbidity. Because multimorbidity is becoming the norm for individuals living with chronic diseases, the traditional disease-oriented approach may be increasingly fragmented, ineffective, and inefficient for patients with chronic diseases. Health care services and policies for chronic diseases, especially in the elderly, have to be developed and implemented within the context of multimorbidity. Integrated and holistic healthcare based on a patient-oriented perspective with a greater awareness of multimorbidity is more appropriate than the traditional disease-oriented approach.

We found that hypertension, dyslipidemia, diabetes mellitus, osteoarthritis, allergic rhinitis, and stroke were the individual conditions that constituted the most frequent dyadic combinations. Another study reported combinations of hypertension, lipid disorder, chronic ischemic heart disease, diabetes mellitus, osteoarthritis, and low back pain as the most frequent multimorbidity $[21,23]$.

The fact that a small number of chronic diseases dominates across the wide number of variants of frequent multimorbidity suggests that one disease may increase the risk of other diseases. For example, hypertension is a known risk factor for cardiovascular disease [24, 25]. Some clusters of specific diseases may share common pathological pathways. In other words, multimorbidity may not be a matter of random chance, but there is a pattern of disease clustering. If that is the case, a future assessment of the patterns of multimorbidity should provide essential information on the possible presence of chronic diseases known to co-occur, and enable active integrated and holistic prevention and management efforts to deal with multimorbidity more effectively.

There is an inverse relationship between the number of chronic conditions and HRQoL [26-29], and this was confirmed in our study. HRQoL is a measure of health status used to assess the medical effectiveness of interventions and to support public health planning, and the EQ-5D is a generic instrument for comparing HRQoL between populations with different conditions [30]. Because chronic diseases are long-lasting and generally cannot be cured, and may contribute to the worsening 
Table 5 Least square means of EQ-5D index score by the degree of multimorbidity and socioeconomic status

\begin{tabular}{|c|c|c|c|c|c|c|}
\hline & \multicolumn{3}{|l|}{50 and older } & \multicolumn{3}{|l|}{65 and older } \\
\hline & Total & Male & Female & Total & Male & Female \\
\hline \multicolumn{7}{|c|}{ Number of chronic conditions } \\
\hline 0 (reference) & $0.94(0.93-0.95)$ & $0.96(0.95-0.96)$ & $0.92(0.91-0.93)$ & $0.88(0.86-0.90)$ & $0.93(0.91-0.95)$ & $0.83(0.79-0.86)$ \\
\hline 1 & $0.90(0.89-0.91)^{*}$ & $0.92(0.91-0.94)^{*}$ & $0.88(0.86-0.89)^{*}$ & $0.86(0.84-0.88)$ & $0.89(0.87-0.92)^{*}$ & $0.83(0.80-0.85)$ \\
\hline 2 & $0.87(0.85-0.88)^{*}$ & $0.90(0.87-0.92)^{*}$ & $0.85(0.84-0.87)^{*}$ & $0.83(0.80-0.85)^{*}$ & $0.86(0.82-0.91)^{*}$ & $0.81(0.78-0.84)$ \\
\hline 3 & $0.81(0.78-0.84)^{*}$ & $0.84(0.79-0.90)^{*}$ & $0.79(0.76-0.82)^{*}$ & $0.77(0.73-0.82)^{*}$ & $0.80(0.70-0.91)^{*}$ & $0.76(0.72-0.80)^{*}$ \\
\hline $4+$ & $0.71(0.67-0.75)^{*}$ & $0.78(0.72-0.84)^{*}$ & $0.68(0.63-0.73)^{*}$ & $0.69(0.64-0.74)^{*}$ & $0.76(0.68-0.84)^{*}$ & $0.67(0.61-0.73)^{*}$ \\
\hline \multicolumn{7}{|l|}{ Marital status } \\
\hline Married (reference) & $0.92(0.91-0.92)$ & $0.93(0.92-0.94)$ & $0.90(0.89-0.91)$ & $0.86(0.85-0.88)$ & $0.89(0.87-0.91)$ & $0.83(0.81-0.85)$ \\
\hline Unmarried & $0.81(0.80-0.83)^{*}$ & $0.87(0.84-0.90)^{*}$ & $0.80(0.78-0.82)^{*}$ & $0.78(0.75-0.80)^{*}$ & $0.85(0.81-0.90)$ & $0.77(0.74-0.79)^{*}$ \\
\hline \multicolumn{7}{|l|}{ Education } \\
\hline High (reference) & $0.95(0.94-0.96)$ & $0.95(0.94-0.96)$ & $0.94(0.93-0.96)$ & $0.92(0.90-0.94)$ & $0.92(0.91-0.94)$ & $0.91(0.88-0.94)$ \\
\hline Low & $0.88(0.87-0.89)^{*}$ & $0.92(0.91-0.93)^{*}$ & $0.86(0.85-0.87)^{*}$ & $0.82(0.80-0.83)^{*}$ & $0.87(0.85-0.89)^{*}$ & $0.79(0.77-0.81)^{*}$ \\
\hline \multicolumn{7}{|l|}{ Household income } \\
\hline Quartile 4 (reference) & $0.95(0.94-0.96)$ & $0.97(0.96-0.98)$ & $0.93(0.92-0.94)$ & $0.90(0.88-0.93)$ & $0.94(0.92-0.96)$ & $0.87(0.83-0.91)$ \\
\hline Quartile 3 & $0.93(0.93-0.94)^{*}$ & $0.96(0.95-0.96)^{*}$ & $0.91(0.90-0.92)^{*}$ & $0.88(0.86-0.90)$ & $0.92(0.90-0.94)$ & $0.84(0.81-0.87)$ \\
\hline Quartile 2 & $0.90(0.89-0.91)^{*}$ & $0.93(0.91-0.94)^{*}$ & $0.87(0.86-0.89)^{*}$ & $0.86(0.83-0.90)^{*}$ & $0.90(0.87-0.94)$ & $0.82(0.79-0.84)^{*}$ \\
\hline Quartile 1 & $0.81(0.79-0.83)^{*}$ & $0.84(0.82-0.87)^{*}$ & $0.79(0.77-0.81)^{*}$ & $0.79(0.77-0.81)^{*}$ & $0.84(0.81-0.87)^{*}$ & $0.76(0.74-0.79)^{*}$ \\
\hline \multicolumn{7}{|c|}{ Basic livelihood security recipients } \\
\hline No (reference) & $0.90(0.90-0.91)$ & $0.93(0.92-0.94)$ & $0.88(0.87-0.89)$ & $0.85(0.83-0.86)$ & $0.89(0.87-0.91)$ & $0.81(0.80-0.83)$ \\
\hline Yes & $0.72(0.68-0.76)^{*}$ & $0.78(0.73-0.83)^{*}$ & $0.68(0.62-0.75)^{*}$ & $0.67(0.61-0.74)^{*}$ & $0.79(0.71-0.87)^{*}$ & $0.63(0.56-0.72)^{*}$ \\
\hline \multicolumn{7}{|l|}{ Occupation } \\
\hline White-collar (reference) & $0.97(0.96-0.97)$ & $0.97(0.97-0.98)$ & $0.95(0.94-0.97)$ & $0.95(0.92-0.97)$ & $0.95(0.92-0.97)$ & $0.93(0.88-0.99)$ \\
\hline Blue-collar & $0.93(0.92-0.94)^{*}$ & $0.95(0.95-0.96)^{*}$ & $0.91(0.89-0.92)^{*}$ & $0.88(0.86-0.89)^{*}$ & $0.92(0.90-0.93)^{*}$ & $0.84(0.82-0.86)^{*}$ \\
\hline Unemployed & $0.84(0.83-0.86)^{*}$ & $0.86(0.84-0.89)^{*}$ & $0.84(0.82-0.85)^{*}$ & $0.81(0.79-0.83)^{*}$ & $0.86(0.83-0.89)^{*}$ & $0.78(0.76-0.80)^{*}$ \\
\hline
\end{tabular}

EQ-5D index score was presented as geometric mean $(95 \% \mathrm{Cl})$

${ }^{*} p<0.05$ compared to reference group

of health and social outcomes [2], managing persons with multimorbidity to achieve a better HRQoL for the rest of their lives is important.

Other studies have found socioeconomic inequalities linked to the prevalence of multimorbidity [31-33]. We found that there is not only a higher prevalence of multimorbidity but also a lower HRQoL among persons with lower socioeconomic status. These results suggest that socioeconomic deprivation plays a role in the development of multimorbidity. Multimorbidity itself also has negative socioeconomic impacts, as it increases the frequency and duration of health services utilization and increases healthcare costs, as mentioned above. As a result, the burden of multimorbidity has a greater influence on groups with lower socioeconomic status and the socioeconomic and health inequality becomes even greater. Therefore, special consideration should be given to patients with low socioeconomic status, with multisector efforts aimed at addressing a range of preventable socioeconomic and behavioral determinants and healthcare costs, thus enhancing health outcomes and quality of life.

The strengths of our study include the relatively large study population, which is representative of the general population of Korea, and that it includes data on quality of life and socioeconomic status. However, some limitations should be acknowledged. The results depend partly on the operational definition of multimorbidity used and the number and type of chronic diseases considered [34]. Fortin et al. reported that if more diseases are considered, a higher prevalence will be estimated [22]. According to Harrisson et al. [35], however, including the 12 most prevalent chronic conditions is sufficient to provide reasonable prevalence estimates when defining multimorbidity as having two or more chronic diseases. We considered 25 chronic diseases, limited to those surveyed by KNHANES, which is a relatively long list of chronic conditions; however, future studies covering the entire spectrum of chronic disease may be required. Our results are likely to be subject to recall bias, since the 
Table 6 Adjusted least square means of EQ-5D index score by the degree of multimorbidity

\begin{tabular}{|c|c|c|c|c|c|c|}
\hline & \multicolumn{3}{|l|}{50 and older } & \multicolumn{3}{|l|}{65 and older } \\
\hline & Total & Male & Female & Total & Male & Female \\
\hline \multicolumn{7}{|l|}{ Sex } \\
\hline Male (Reference) & $0.82(0.80-0.85)$ & & & $0.81(0.77-0.86)$ & & \\
\hline Female & $0.81(0.78-0.83)^{*}$ & & & $0.79(0.74-0.83)^{*}$ & & \\
\hline \multicolumn{7}{|c|}{ Number of chronic conditions } \\
\hline 0 (reference) & $0.88(0.85-0.91)$ & $0.91(0.88-0.94)$ & $0.86(0.82-0.90)$ & $0.86(0.81-0.91)$ & $0.94(0.88-0.99)$ & $0.83(0.77-0.90)$ \\
\hline 1 & $0.86(0.83-0.88)^{*}$ & $0.89(0.86-0.92)^{*}$ & $0.84(0.81-0.88)^{*}$ & $0.85(0.80-0.89)$ & $0.90(0.85-0.96)^{*}$ & $0.84(0.79-0.90)$ \\
\hline 2 & $0.84(0.82-0.87)^{*}$ & $0.87(0.83-0.90)^{*}$ & $0.83(0.80-0.87)^{*}$ & $0.82(0.78-0.86)^{*}$ & $0.87(0.81-0.93)^{*}$ & $0.82(0.76-0.88)$ \\
\hline 3 & $0.80(0.76-0.83)^{*}$ & $0.83(0.77-0.89)^{*}$ & $0.78(0.74-0.83)^{*}$ & $0.78(0.73-0.84)^{*}$ & $0.82(0.72-0.93)^{*}$ & $0.79(0.73-0.86)$ \\
\hline $4+$ & $0.71(0.66-0.75)^{*}$ & $0.76(0.71-0.82)^{*}$ & $0.68(0.63-0.74)^{*}$ & $0.70(0.64-0.76)^{*}$ & $0.77(0.67-0.88)^{*}$ & $0.69(0.62-0.77)^{*}$ \\
\hline \multicolumn{7}{|l|}{ Marital status } \\
\hline Married (reference) & $0.83(0.81-0.86)$ & $0.86(0.83-0.88)$ & $0.82(0.78-0.86)$ & $0.81(0.77-0.85)$ & $0.86(0.81-0.91)$ & $0.81(0.76-0.87)$ \\
\hline Unmarried & $0.80(0.77-0.82)^{*}$ & $0.84(0.80-0.88)$ & $0.78(0.74-0.82)^{*}$ & $0.79(0.74-0.83)^{*}$ & $0.86(0.79-0.93)$ & $0.77(0.72-0.83)^{*}$ \\
\hline \multicolumn{7}{|l|}{ Education } \\
\hline High (reference) & $0.83(0.80-0.86)$ & $0.86(0.83-0.89)$ & $0.82(0.78-0.86)$ & $0.83(0.79-0.88)$ & $0.88(0.82-0.95)$ & $0.84(0.78-0.90)$ \\
\hline Low & $0.80(0.77-0.82)^{*}$ & $0.84(0.81-0.86)^{*}$ & $0.78(0.74-0.82)^{*}$ & $0.77(0.73-0.81)^{*}$ & $0.83(0.78-0.89)^{*}$ & $0.75(0.70-0.80)^{*}$ \\
\hline \multicolumn{7}{|l|}{ Household income } \\
\hline Quartile 4 (reference) & $0.84(0.81-0.86)$ & $0.87(0.84-0.90)$ & $0.82(0.78-0.86)$ & $0.83(0.78-0.88)$ & $0.88(0.83-0.95)$ & $0.82(0.76-0.89)$ \\
\hline Quartile 3 & $0.83(0.81-0.86)$ & $0.87(0.84-0.90)$ & $0.82(0.78-0.86)$ & $0.81(0.77-0.86)$ & $0.87(0.82-0.94)$ & $0.80(0.74-0.87)$ \\
\hline Quartile 2 & $0.81(0.79-0.84)^{*}$ & $0.85(0.82-0.89)^{*}$ & $0.79(0.76-0.84)^{*}$ & $0.79(0.75-0.84)^{*}$ & $0.86(0.79-0.93)$ & $0.78(0.72-0.84)^{*}$ \\
\hline Quartile 1 & $0.77(0.75-0.80)^{*}$ & $0.81(0.78-0.84)^{*}$ & $0.76(0.72-0.79)^{*}$ & $0.77(0.73-0.81)^{*}$ & $0.81(0.76-0.87)^{*}$ & $0.76(0.71-0.82)^{*}$ \\
\hline \multicolumn{7}{|c|}{ Basic livelihood security recipients } \\
\hline No (reference) & $0.86(0.85-0.88)$ & $0.89(0.86-0.91)$ & $0.86(0.84-0.87)$ & $0.87(0.85-0.88)$ & $0.88(0.85-0.92)$ & $0.87(0.85-0.90)$ \\
\hline Yes & $0.77(0.72-0.81)^{*}$ & $0.81(0.77-0.86)^{*}$ & $0.74(0.68-0.81)^{*}$ & $0.74(0.67-0.81)^{*}$ & $0.83(0.74-0.93)$ & $0.72(0.63-0.81)^{*}$ \\
\hline \multicolumn{7}{|l|}{ Occupation } \\
\hline White-collar (reference) & $0.82(0.79-0.85)$ & $0.86(0.83-0.89)$ & $0.80(0.76-0.85)$ & $0.81(0.76-0.86)$ & $0.87(0.81-0.93)$ & $0.81(0.74-0.89)$ \\
\hline Blue-collar & $0.83(0.81-0.86)^{*}$ & $0.87(0.84-0.90)$ & $0.81(0.78-0.85)$ & $0.82(0.78-0.86)$ & $0.88(0.81-0.94)$ & $0.81(0.75-0.86)$ \\
\hline Unemployed & $0.79(0.77-0.82)^{*}$ & $0.82(0.79-0.89)^{*}$ & $0.78(0.74-0.81)^{*}$ & $0.77(0.74-0.81)^{*}$ & $0.83(0.78-0.89)$ & $0.76(0.71-0.81)^{*}$ \\
\hline
\end{tabular}

Adjusted for marital status, education, household income, basic livelihood security recipient status, and occupation Sex was additionally adjusted when analyzed with total including both sex ${ }^{*} p<0.05$ compared to reference group

chronic diseases were based on self-reports, and selection bias, as only the non-institutionalized Korean population was included in the survey. However, we expect that the direction of these biases is toward the null and the real effect of multimorbidity would be greater than determined here.

\section{Conclusions}

There is a high prevalence of multimorbidity and lower HRQoL in Korean adults experiencing multimorbidity, especially the female elderly with lower socioeconomic status. Taking into consideration the large disease and economic burden of multimorbidity and its negative effects on HRQoL, the development of appropriate guidelines for the integrated, co-operative management of multiple chronic diseases is warranted. We expect the results of this study to be used as an evidence base to devise informed healthcare for the effective care of patients with multimorbidity.

\section{Abbreviations}

Cl: Confidence interval; EQ-5D: EuroQol five-dimension; HRQoL: Healthrelated quality of life; KCDC: Korean Centers for Disease Control and Prevention; KNHANES: Korean National Health and Nutrition Examination Survey; SE: Standard error

\section{Funding}

This study was supported by a grant from the Korean Health Technology R\&D Project, Ministry of Health \& Welfare, Republic of Korea (grant number: HI13C0729, http://www.khidi.or.kr/kps). The funder had no role in study design, data collection and analysis, decision to publish, or preparation of the manuscript. 


\section{Availability of data and materials}

The datasets supporting the conclusions of this article are available in the Korea Centers for Disease Control and Prevention website (https:// knhanes.cdc.go.kr/knhanes/sub03/sub03_02_02.do).

\section{Authors' contributions}

BP participated in the study design, performed the statistical analysis, interpreted the data, and drafted the manuscript. MO and HAL participated in the interpretation of the data and revised the manuscript. $S \mathrm{~L}$ and $\mathrm{HH}$ made contributions to the study design as well as interpretation of the data. MWJ helped the interpretation of the data. HP conceived of the study and participated substantially in its design and coordination. All authors read and approved the final manuscript.

\section{Ethics approval and consent to participate}

This study was approved by the institutional review board of KCDC (201307CON-03-4C, 2013-12EXP-03-5C), and informed consent to participate in the study was obtained from all participants.

\section{Consent for publication}

Not applicable.

\section{Competing interests}

The authors declare that they have no competing interests.

\section{Publisher's Note}

Springer Nature remains neutral with regard to jurisdictional claims in published maps and institutional affiliations.

\section{Author details}

'Department of preventive medicine, School of Medicine, Ewha Womans University, Seoul, South Korea. ${ }^{2}$ Department of Preventive Medicine, Ulsan University Hospital, University of Ulsan College of Medicine, Ulsan, South Korea. ${ }^{3}$ Clinical Trial Center, Mokdong Hospital, Ewha Womans University, Seoul, South Korea. ${ }^{4}$ Department of Preventive Medicine, University of Ulsan College of Medicine, Seoul, South Korea.

Received: 19 February 2018 Accepted: 7 September 2018 Published online: 15 September 2018

\section{References}

1. van den Akker M, Buntinx F, Metsemakers JF, Roos S, Knottnerus JA. Multimorbidity in general practice: prevalence, incidence, and determinants of co-occurring chronic and recurrent diseases. J Clin Epidemiol. 1998;51: 367-75.

2. Fortin M, Lapointe L, Hudon C, Vanasse A, Ntetu AL, Maltais D. Multimorbidity and quality of life in primary care: a systematic review. Health Qual Life Outcomes. 2004:2:51.

3. Kim Kl, Lee JH, Kim CH. Impaired health-related quality of life in elderly women is associated with multimorbidity: results from the Korean National Health and nutrition examination survey. Gend Med. 2012;9:309-18.

4. Menotti A, Mulder I, Nissinen A, Giampaoli S, Feskens EJ, Kromhout D. Prevalence of morbidity and multimorbidity in elderly male populations and their impact on 10-year all-cause mortality: the FINE study (Finland, Italy, Netherlands, elderly). J Clin Epidemiol. 2001;54:680-6.

5. Gijsen R, Hoeymans N, Schellevis FG, Ruwaard D, Satariano WA, van den Bos GA. Causes and consequences of comorbidity: a review. J Clin Epidemiol. 2001;54:661-74.

6. Williams JS, Egede LE. The association between multimorbidity and quality of life, health status and functional disability. Am J Med Sci. 2016;352:45-52.

7. Fortin M, Bravo G, Hudon C, Lapointe L, Almirall J, Dubois MF, et al. Relationship between multimorbidity and health-related quality of life of patients in primary care. Qual Life Res. 2006;15:83-91.

8. McPhail SM. Multimorbidity in chronic disease: impact on health care resources and costs. Risk Manag Healthc Policy. 2016;9:143-56.

9. Lehnert T, Heider D, Leicht H, Heinrich S, Corrieri S, Luppa M, et al. Review: health care utilization and costs of elderly persons with multiple chronic conditions. Med Care Res Rev. 2011;68:387-420.

10. Starfield B, Lemke KW, Herbert R, Pavlovich WD, Anderson G. Comorbidity and the use of primary care and specialist care in the elderly. Ann Fam Med. 2005;3:215-22.
11. Marengoni A, Angleman S, Melis R, Mangialasche F, Karp A, Garmen A, et al. Aging with multimorbidity: a systematic review of the literature. Ageing Res Rev. 2011;10:430-9.

12. KOSIS. Population projections: general and processed statistics, statistics on population. Available from: http://www.kosis.kr Cited 17 November 2017.

13. Lee YK, Nam HS, Chuang LH, Kim KY, Yang HK, Kwon IS, et al. South Korean time trade-off values for EQ-5D health states: modeling with observed values for 101 health states. Value Health. 2009;12:1187-93.

14. OECD. Terms of reference OECD project on the distribution of household incomes. Available from: http://www.oecd.org/els/soc/IDD-ToR.pdf Cited 20 August 2018.

15. Barnett K, Mercer SW, Norbury M, Watt G, Wyke S, Guthrie B. Epidemiology of multimorbidity and implications for health care, research, and medical education: a cross-sectional study. Lancet. 2012;380:37-43.

16. Orueta JF, Garcia-Alvarez A, Garcia-Goni M, Paolucci F, Nuno-Solinis R. Prevalence and costs of multimorbidity by deprivation levels in the Basque Country: a population based study using health administrative databases. PLoS One. 2014;9:e89787.

17. Britt HC, Harrison CM, Miller GC, Knox SA. Prevalence and patterns of multimorbidity in Australia. Med J Aust. 2008;189:72-7.

18. Roberts KC, Rao DP, Bennett TL, Loukine L, Jayaraman GC. Prevalence and patterns of chronic disease multimorbidity and associated determinants in Canada. Health Promot Chronic Dis Prev Can. 2015:35:87-94.

19. Anderson $\mathrm{G}$, Horvath J. The growing burden of chronic disease in America. Public Health Rep. 2004;119:263-70.

20. Wolff IL, Starfield B, Anderson G. Prevalence, expenditures, and complications of multiple chronic conditions in the elderly. Arch Intern Med. 2002;162:2269-76.

21. van den Bussche H, Koller D, Kolonko T, Hansen $H$, Wegscheider $\mathrm{K}$, Glaeske $\mathrm{G}$, et al. Which chronic diseases and disease combinations are specific to multimorbidity in the elderly? Results of a claims data based cross-sectional study in Germany. BMC Public Health. 2011;11:101.

22. Fortin M, Stewart M, Poitras ME, Almirall J, Maddocks H. A systematic review of prevalence studies on multimorbidity: toward a more uniform methodology. Ann Fam Med. 2012;10:142-51.

23. Laux G, Kuehlein T, Rosemann T, Szecsenyi J. Co-and multimorbidity patterns in primary care based on episodes of care: results from the German CONTENT project. BMC Health Serv Res. 2008;8:14.

24. Padwal R, Straus SE, McAlister FA. Evidence based management of hypertension. Cardiovascular risk factors and their effects on the decision to treat hypertension: evidence based review. BMJ. 2001;322:977-80.

25. Bromfield S, Muntner P. High blood pressure: the leading global burden of disease risk factor and the need for worldwide prevention programs. Curr Hypertens Rep. 2013;15:134-6.

26. Agborsangaya CB, Lau D, Lahtinen $M$, Cooke T, Johnson JA. Health-related quality of life and healthcare utilization in multimorbidity: results of a crosssectional survey. Qual Life Res. 2013;22:791-9.

27. Cheng L, Cumber S, Dumas C, Winter R, Nguyen KM, Nieman LZ. Health related quality of life in pregeriatric patients with chronic diseases at urban, public supported clinics. Health Qual Life Outcomes. 2003;1:63.

28. N'Goran AA, Deruaz-Luyet A, Haller DM, Zeller A, Rosemann T, Streit S, et al. Comparing the self-perceived quality of life of multimorbid patients and the general population using the EQ-5D-3L. PLoS One. 2017;12:e0188499.

29. Michelson H, Bolund C, Brandberg Y. Multiple chronic health problems are negatively associated with health related quality of life (HRQOL) irrespective of age. Qual Life Res. 2000;9:1093-104.

30. Hunger M, Thorand B, Schunk M, Doring A, Menn P, Peters A, et al. Multimorbidity and health-related quality of life in the older population: results from the German KORA-age study. Health Qual Life Outcomes. 2011;9:53.

31. Katikireddi SV, Skivington K, Leyland AH, Hunt K, Mercer SW. The contribution of risk factors to socioeconomic inequalities in multimorbidity across the lifecourse: a longitudinal analysis of the Twenty-07 cohort. BMC Med. 2017;15:152.

32. Schiotz ML, Stockmarr A, Host D, Glumer C, Frolich A. Social disparities in the prevalence of multimorbidity —a register-based population study. BMC Public Health. 2017:17:422.

33. Ki M, Lee YH, Kim YS, Shin JY, Lim J, Nazroo J. Socioeconomic inequalities in health in the context of multimorbidity: a Korean panel study. PLoS One. 2017;12:e0173770. 
34. van den Akker M, Buntinx F, Roos S, Knottnerus JA. Problems in determining occurrence rates of multimorbidity. J Clin Epidemiol. 2001;54:675-9.

35. Harrison $\mathrm{C}$, Britt $\mathrm{H}$, Miller $\mathrm{G}$, Henderson J. Examining different measures of multimorbidity, using a large prospective cross-sectional study in Australian general practice. BMJ Open. 2014;4:e004694.

Ready to submit your research? Choose BMC and benefit from:

- fast, convenient online submission

- thorough peer review by experienced researchers in your field

- rapid publication on acceptance

- support for research data, including large and complex data types

- gold Open Access which fosters wider collaboration and increased citations

- maximum visibility for your research: over $100 \mathrm{M}$ website views per year

At $B M C$, research is always in progress.

Learn more biomedcentral.com/submissions 